Ophthalmic examination-Vision $6 / 60$ both eyes. With the corneal microscope the anterior cortical layer of the lenses was normal. Small linear opacities with very small vacuoles varying from 0.05 to $0.10 \mathrm{~mm}$. in size were seen in the posterior subcapsular layer of the lenses.

It is of interest that the operations for the removal of the cataract in these cases were not difficult, the lenses separated very easily and there was no trouble with haemorrhage.

I have seen a number of cases of severe diabetes in young children with high urine and blood sugars whose vision was normal, but the duration of the disease had not been long enough to cause lens changes, and when they received appropriate treatment to bring down the sugar percentage to nearly normal in the blood, lens opacities did not occur.

Before the removal of senile cataracts in diabetes, one must be very careful to bring down the blood sugar to nearly normal or normal before operation. Haemorrhage is usually troublesome and often leads to a dense after cataract.

At the time of operation, it is always wise to irrigate all soft lens matter from the anterior chamber and then perform a small buttonhole iridectomy in preference to a complete iridectomy. The less the iris is injured, the less the haemorrhage and the less chance of a dense posterior capsule afterwards.

\title{
REFERENCES
}

Foster Moore.-Medical Ophthalmology, 1925.

Maynard.-Manual of Ophthalmic Practice, 1920.

\section{MICROPHTHALMOS WITH CONGENITAL DEFECT OF THE LACRIMAL APPARATUS}

\author{
BY \\ S. Silverman, B.Sc., M.B.Ch.B. \\ Clinical assistant, QUEEN'S hospital, BIRMINGHAM
}

THE following case of a congenital abnormality of the left eye and lacrimal apparatus in a premature female infant which survived for three and a half months is sufficiently rare to justify record and description.

The mother, aged 35 years, has two childen, a boy, aged 14 years and a girl, aged 10 years. Her Wassermann reaction was negative. The father is 43 years of age. No congenital abnormalities are traceable in the parents, children or family, though the 
boy and two cousins on the mother's side suffer from acquired strabismus.

The mother had a severe degree of toxaemia during pregnancy. Labour was due on December 11, 1932, but commenced insidiously on October 25.

The infant was a twin, being born first, presenting as a vertex. The other, a male infant, was still-born, presenting as a breech.

The female infant weighed $3 \mathrm{lbs} .2$ ozs. at birth. The eyelids were normal, but on separating the lids of the left eye to instil one per cent. silver nitrate drops, the surface of what was taken for the eyeball presented a greyish uniform haze, there being no sign of cornea or pupil. Apart from the signs of prematurity no other abnormalities were detected.

For the first few days the baby was very restless and had little sleep. It was admitted to Sorrento Maternity Home, Birmingham, on October 29, 1932.

When the baby opened its left eye and looked towards the light, a glimpse was obtained of something dark in the outer corner. This was taken to be part of the iris, the remainder being covered with a greyish opaque structure. On pressure over the closed eyelid the eyeball was not soft, but the tension was slightly less than that of the right eyeball.

On February 1, 1933, broncho-pneumonia developed, to which the baby succumbed on February 8 .

On post-mortem examination the evelids were normal. On the right side they covered an eyeball of normal formation, $20 \mathrm{~mm}$. in diameter, with a cornea $8 \mathrm{~mm}$. in diameter, but it presented a coloboma of the iris at its lower pole on a base of $3 \mathrm{~mm}$. extending almost through the whole of the iris. On the left side there first was seen on separating the eyelids a cystic structure in the position of the lacrimal sac, the size of a small grape $18 \mathrm{~mm}$. in diameter.

There was a punctum lacrimale in the upper lid in the normal position, a bristle inserted into which entered the cavity of the cyst. A punctum was present in the normal position in the lower lid but a bristle inserted into this could not be made to enter the cyst, nor could any communication with the nose via a nasal duct be made out. 'The wall of the cyst was of tough fibro-cellular structure. The cyst was tense and contained colourless serous fluid. This structure had pushed what was apparently a normal eyeball into the outer part of the orbital cavity. But on careful examination it was found that this eyeball, apart from being flattened by pressure from side to side, was smaller than its neighbour, being $16 \mathrm{~mm}$. in diameter wih a cornea $7 \mathrm{~mm}$. in diameter. It had a normal sclerotic, cornea and pupil, but there was a colobomatous defect in the iris at the lower pole, corres- 
ponding to the one on the other side, with a base of $2 \mathrm{~mm}$., and extending almost to the corneal margin.

A review of the literature on the subject fails to reveal any analogous case having been reported, though Goar ${ }^{1}$ describes a case of congenital atresia of the left puncta and lacrimal canals and mentions similar cases which have been recorded.

The lacrimal passages according to Whitnall ${ }^{2}$ are developed along the line of the cleft between the lateral nasal and maxillary processes of the embryonic face by the canalization of a solid rod of ectodermal cells formed beneath the surface along the line of the cleft.

The puncta and inferior orifice of the nasal duct are the last to canalize, the former open just before the eyelids separate, about the seventh month, the latter at the end of the eighth month or not till after birth.

As to the pathological nature of the cyst the possibilities are :-

1. Cyst of the lacrimal sac; this is most likely as the cyst communicated with the punctum in the eyelid and was in the position of the sac.

2. Dermoid; this is not likely as no dermoid contents were discoverable, and it was not quite in the usual position for a dermoid.

3 . Congenital cyst associated with microphthalmos; the eyeball was smaller than the normal one and also flattened by the cyst pressure, but the situation and connections of the cyst would exclude it from being purely of this nature.

4. Meningocele; this is ruled out by there being no trace of communication via the bony wall of the orbit with the cranial cavity.

On the whole this would seem to be an instance of overgrowth and distention of the lacrimal sac with arrested development of the left eyeball and incomplete canalization of the inferior canaliculus and nasal duct combined with some slight failure in the normal involution of both choroidal fissures.

In conclusion I wish to express my thanks to Dr. V. Mary Crosse, medical officer to the Sorrento Maternity Home, for her helpful observations and careful examination of the eyes post-mortem.

\section{REFERENCES}

1. Goar, L.-A rch. of Ophthal., Vol. VI, No. 5, p. 724, November, 1931.

2. Whitnall, S. E.-Anatomy of the Human Orbit and Accessory Organs of Vision. p. 245. Oxford University Press. 1921. 